El Guiniguada • Revista de investigaciones y experiencias en Ciencias de la Educación

\title{
EL RETO DE PUBLICAR UNA REVISTA DE INVESTIGACIÓN: UNA REFLEXIÓN PERSONAL
}

\author{
José Antonio Ibáñez-Martín \\ Revista Española de Pedagogía
}

Recibido: 01/02/2015/Aceptado: 02/03/2015

Forma parte de la tradición hablar, en la primera clase de una asignatura, acerca de su importancia y del mucho tiempo que a ella debe dedicarse. Los alumnos suelen recibir esas ideas de un modo diverso. Si el profesor ha puesto fuego en su exposición, unos piensan que no es preciso hacer caso a esas ideas, pues le ven como parte interesada, mientras que otros se alegran pensando que, al menos, el profesor cree en la importancia de lo que enseña.

Esta observación me obliga advertir al lector que, yo, efectivamente, soy parte interesada. Llevo el último tercio de siglo dirigiendo la Revista Española de Pedagogía, de la que estoy muy orgulloso pues ha sido la primera revista de investigación pedagógica, escrita principalmente en español, que ha sido llamada para formar parte del selecto grupo de revistas del mundo entero que se encuentran en la sección de investigación educativa de la base de datos más cualificada, que es el Journal Citation Reports. Quizá ese orgullo se pueda pensar que limitará la objetividad de este breve escrito, pero confío en que, al menos, mis palabras muevan al lector a pensar que verdaderamente creo en la importancia de lo que a continuación defiendo.

Quizá me equivoque en la forma de abordar algún asunto pero mi experiencia en este tema me lleva a afirmar que es oportuno desarrollar, con la brevedad requerida, tres preguntas esenciales. Concretamente, me parece que es preciso reflexionar sobre la importancia de las revistas en el desarrollo de la ciencia, así como preguntarse qué cabe esperar del trabajo de la dirección de una revista y qué cabe pedir a los que desean publicar en ella.

\section{LA IMPORTANCIA DE LAS REVISTAS EN EL DESARROLLO DE LA CIENCIA}

A veces hay quienes desprecian las revistas y afirman que solo contienen temas secundarios pues el verdadero avance del saber científico reposa en los libros. 
Sería poco razonable descalificar ahora la importancia de los libros, pero se lucha contra la evidencia cuando se descalifica el papel de la revista. Hace pocos años, la revista Annalen der Physike dedicaba un número especial a los artículos que Einstein había publicado. Comenzó a publicar en el 1901, cuando era un joven desconocido de 22 años que no se movía en el mundo universitario, y hasta 1922 publicó 49 trabajos, entre los que me limitaré a señalar el artículo del $1905^{2}$ en el que propone su famosa teoría de la relatividad especial. En esta misma línea, podemos situar, unos años antes, el seminal trabajo de Henri Poincaré, titulado "Analysis Situs"3, que representa la primera mirada sistemática de la topología.

La lista sería interminable. Por ello, me limitaré a recordar un artículo publicado en una revista canaria del año 2000, que hace una exposición de los avances de las matemáticas a lo largo del siglo XX, donde pueden verse las teorías que en las revistas han visto la luz ${ }^{4}$. Y ante esos hechos no cabe decir que hoy internet ha convertido en inútiles a las revistas. En efecto, esa argumentación llevaría también a arrumbar a los libros y a olvidar que las grandes revistas, como las editoriales de prestigio, tienen la misma función que los grandes directores de cine: ante la infinita información que nos llega a través de internet el filtro de la gran revista es el que nos lleva a acudir a lo que tiene un sello de calidad, ese sello que sabemos imprime un aire especial a las películas de John Ford.

\section{2. ¿QUUE CABE ESPERAR DEL TRABAjo DE LA DIRECCIÓN DE UNA REVISTA CIENTÍFICA?}

Me parece que es justo señalar la dureza del trabajo de dirección de una revista. Generalmente se gana muy poco dinero (en el caso, más bien minoritario, de que se gane alguno), se le tiene que dedicar mucho tiempo y se cosechan no pocos disgustos cuando hay que rechazar originales, a veces de amigos o incluso de miembros del consejo editorial (los agradecimientos se dan también, pero tienden a ser menores, pues los autores solemos pensar que nuestro trabajo es extraordinario).

Esas escasas compensaciones -aunque no debamos olvidar la alegría ante la obra bien hecha y el apoyo a la excelencia, que a veces se descubre en personas desconocidas- exigen responder adecuadamente a los objetivos básicos de dicha tarea, que uno es formal y otro es material. Formalmente hablando, la dirección debe procurar que

1 Annalen der Physik, 2005, 14, 1-3.

2 Einstein, A. (1905). Zur Elektrodynamik bewegter Körper, Annalen der Physik, 17, 891.

3 Poincaré, H. (1895). "Analysis Situs", Journal de l’École Polytecbnique, 2,1, 1-123.

4 AA.VV. (2000). "Las matemáticas del siglo XX: una mirada en 101 artículos", Números, 43-44.

El Guiniguada, 23 (2014) • pp. 15-18 • eISSN: 2386-3374 
el diseño de la revista sea bello, así como está obligada a que la revista proporcione, de modo siempre igual, todos los datos bibliográficos exigidos por las normas internacionales y a que los números aparezcan sin erratas en las fechas previstas. Materialmente, se trata de conseguir que los artículos publicados sean de verdadera calidad, adecuados al objeto de la revista y capaces de suscitar el interés. En esta meta, es muy importante la colaboración de los evaluadores, que deben actuar siguiendo el principio de la doble ceguera (no saben a quién corrigen ni los corregidos conocen quién les evalúa).

\section{3. ¿QUÉ CABE PEDIR A QUIENES DESEAN PUBLICAR EN UNA REVISTA CIENTÍ- FICA?}

Evidentemente la exigencia básica a los autores es la honestidad. Quienes creen que todo el mundo es bueno, en la dirección de una revista se llevarían muchos disgustos. Hoy, la facilidad de cortar y pegar lo que se lee en internet, nos obliga a tener programas que señalan la paternidad real de las afirmaciones de los textos recibidos. Pero, junto a ello, hay no pocas otras cuestiones. Quizá las más graves son la falsedad en los datos o la descalificación por motivos ideológicos de las teorías científicas. Entre los casos más conocidos se encuentra el de Sir Cyril Burt, Catedrático de Psicología de la Educación de la Universidad de Londres y director de una conocida revista, que, en torno a la Segunda Guerra Mundial, pretendió basar su tesis de la importancia absoluta de la herencia genética sobre la inteligencia de las personas - por encima de cualquier influencia del ambiente- en datos recogidos sobre gemelos univitelinos crecidos en ambientes distintos, datos que se descubrió tras su muerte que eran inventados. Por otra parte, tenemos el caso de Lysenko, quien bajo la dictadura de Stalin, impuso en la URSS una falsa genética, por considerar que ésta debía basarse en el materialismo dialéctico y no como la genética de Mendel, que no sólo no era ateo sino que era un fraile agustino ${ }^{5}$. Junto a ella, hay otras deshonestidades a considerar, cabría decir de menor cuantía, pero no irrelevantes. Por citar dos casos que me han ocurrido: a) una vez aprobado un artículo para su publicación, el autor me mandó la versión definitiva, en la que ya no era él solo el autor sino que aparecía otra persona; quizá era un acto tardío de justicia, pero me parece que, más bien, era un trato de injusticia: yo te pongo a ti, donde no has trabajado, y tú me colocas, donde yo no he trabajado. b) en una ocasión, como experto de la ANECA, me llegó un currículum de una persona que deseaba acreditarse como Titular. Me alegré al ver que tenía un artículo publicado hacía dos años en la Revista Española de Pedagogía,

5 Sobre este tema es muy interesante el trabajo de Shulz, P.C. y Katime, I., "Los fraudes científicos", Revista Iberoamericana de Polimeros, 2003, 4:2, abril, 1-90. 
pero mi decepción fue grande cuando observé que había publicado otro en una revista inglesa, medio año más tarde, que tenía un título semejante: acudí a la revista y era la exacta traducción del artículo ya publicado.

Ahora bien, naturalmente, esos horrores se dan pocas veces. Lo que normalmente hay que exigir es que los autores deseen promover el aumento de la ciencia y no el engorde de su currículum, pretendiendo publicar cosas superficiales, carentes de interés científico. Nada hay menos interesante, por mucho manejo estadístico que se dé a los datos recogidos, que analizar una encuesta de opinión que has hecho a tus alumnos; desgraciadamente no son pocos los que pretenden publicar cosas semejantes.

Termino con una felicitación y una propuesta. Primero, felicito a la directora de esta revista por la iniciativa que comienza a desarrollar. Por otra parte, me permito hacer una propuesta. Todo orador tiene su público, como toda revista. Todo orador mira la actitud de su público y la tiene en cuenta en el desarrollo de su discurso. Los directores de revistas agradeceríamos a nuestro público que nos mandaran e-mails contando su reacción ante la revista y ante los artículos leídos.

josibama@edu.ucm.es 